reproduction and the social good and fears by dominant groups of higher population growth in other groups (what one British expert has called 'competitive tribalism'). One author even offers a variant of the 'yellow peril' theme: fear that the First World will lose its world primacy.

There is much discussion about the human right to control fertility and the extent to which this has to be seen in context. One author asserts that the right is not fundamental but must take account of responsibilities to the self, to others and to the next generation. No author dissents from the proposition that the decline of external moral absolutism and advances in contraceptive technology have led to greater individual choice - and hence to greater individual moral responsibility. Women, in particular, have gained control over their sexual lives, while individuals generally have been able to avoid some of the undesirable results of sexual activity. However, contraception has not radically changed attitudes to human sexuality. We are told that sexual behaviour is a complex human activity in which sexual attitudes determine the acceptability of contraception rather than the reverse.

The relationship between individual responsibility and external guidance is considered in the context of the sexual behaviour of minors and the role of public health workers providing contraceptive services to them. The question is whether medical providers should be moral educators. Although medical morality has replaced religious morality, this has not avoided conflicts of moral value both for providers and clients of contraceptive services.

Two authors deal with the relationship between population growth and development, a theme occupying increasing attention in international institutions concerned with development. How population growth relates to national welfare is an 'intricate problem'; when is government intervention morally justified? China's coercive one-child policy raises ethical issues. It is concluded that such issues have to be considered in the context of the values of those involved and the claims of the communities affected.

This book provides a stimulating and informative debate on a wide-ranging topic. It touches (too briefly) on the issue of individual responsibility to future generations but deliberately avoids the matter of individual responsibility for what happens to other life on earth as world population growth puts such life under ever greater pressure. Those major moral issues must impinge on sexual behaviour.

Any further symposium on this topic should deal with Sexually Transmitted Diseases (STDs) and include one or more contributors from the Third World where the pressures of excessive population growth could produce new moral and philosophical insights.

ERIC DEAKINS Population Concern, London

\section{Sharing the Darkness: The Spirituality of Caring}

Sheila Cassidy, 164 pages, London, £5.95, Darton, Longman and Todd, 1988

Everyone, so we are told, has a book in them. Sharing the Darkness is that kind of book and its spirituality is personal.

Dr Sheila Cassidy was thrust into the limelight when in 1975, having treated a wounded revolutionary in Chile where she was then working, she was herself arrested and tortured. It was a remarkable story of personal courage and I remember hearing her on the radio describing in a most moving way the spiritual aspect of this experience (more fully recalled in her book Audacity to Believe). In this present book she refers to this terrible incident in passing. More recently she has become well known as the Medical Director of St Luke's Hospice, Plymouth, which was featured in the TV series The Visit. It is from this experience of terminal care, which has been her concern for the past nine years, that she draws the main themes for her book.

When these two aspects of her life are in mind her writing is at its best. While critical of attitudes which sometimes make professionals appear uncaring she nevertheless explains the process and the system which can bring this about. She considers communication of 'bad news' and provides a thoughtful chapter entitled Hospice as Community, in which she confronts the tensions of stressed working relationships finding 'natural' support groups more useful than 'facilitated' ones in helping to bring about some resolution.

If the book is something of a patchwork wrought from stuff of varied quality and having no easily discernible pattern overall, at least in her Introduction the author lets us know she is aware that this is so. It was a bookm she had to write. The subtitle is perhaps $\underset{\bar{\tau}}{\text {. }}$ then misleading for it is not a systematice theology of caring.

The poignant illustrations which canos hold the attention of an audience for ao lecture, broadcast - talk or sermon, can appear maudlin when written. I found $\bar{c}$. this especially so in her description of hospice patients or members of the L'Arche Community in their work. As v she says: 'It is difficult to write without $\overrightarrow{-}$ sounding sentimental'.

This aside, the book will be most $\overrightarrow{\vec{\omega}}$ appreciated by those who find theo autobiographical jottings of others helpful in charting their own journeyc through life and who are taking soundings to discover the spiritual bed $-\omega$ rock. If it does raise more questions than it answers then this is an inevitablec part of that voyage of discovery that haso to be made in the matter of faith as in other matters of human knowledge. It is $(s)$ an honest attempt to grapple with important issues of belief and especially ${ }_{\mathbb{D}}$ with the problem of pain and suffering. It is by someone who has experienced pain acutely herself and has continued to observe it closely in the sufferingscofo her patients as well as in herself and here co-workers while attempting, throush professional skills, to bring relief and comfort to those in their care. Above alls it is a book by someone who cares passionately about her work and iso seeking to understand its spirituab dimension. Sheila Cassidy did test her vocation to the religious life when she entered a convent but she returned tomedicine eighteen months later knowing that way of life was not to behers. She is concerned not just about the love of God but also about the love of neighbour. Here is no spiritual flight of fancy, for her writings are related to the real world (Meister Ekhart, St Ignatius, Annie Dillard, Helder Camara are among her guides) ... it is incarnational.음

I look forward to Sheila Cassidy's more systematic development of these important themes in what I hope will be a series of further writings. Meanwhiles Sharing the Darkness provides a usefuh starting point for discussion and for prayerful reflection.

TREVOR MORLEY Chaplain to University College्ष Hospital, Londore?

\section{Maitre De La Vie}

Charles Lefevere, 215 pages, Paris, FF 95, Le Centurion, 1987 